\title{
A New Method of Manufacturing Thin-Walled Tube Made of AZ61 Magnesium Alloy Including Direct Extrusion And Corrugated Equal Channel Angular Extrusion
}

\section{H-J Hu ( $248516686 @ Q Q . C O M)$}

Materials Science and Engineering College Chongqing Institute of Technology

Ou Zhang

Chongqing University of Technology

Gang Hu

Chongqing University of Technology

Hui Zhao

Chongqing University of Technology

Zhongwen OU

Chongqing University of Technology

\section{Research Article}

Keywords: AZ61 magnesium alloy, Simulation, Grain refinement, Thin-walled tube, Dynamic recrystallization

Posted Date: October 18th, 2021

DOl: https://doi.org/10.21203/rs.3.rs-969216/v1

License: (c) (i) This work is licensed under a Creative Commons Attribution 4.0 International License.

Read Full License 


\section{Abstract}

Due to demand of strong toughness of thin walled tube, and good secondary forming properties and high-precision dimension, New plastic forming method should be researched to achieve a complete filling, uniform deformation and microstructure evolution during forming process.To obtain the deformation mechanisms of a new composite extrusion for thin walled tube fabricated by tube corrugated equal channel angular extrusion has been researched which is shorten as "TC-ECAE" in this paper. Finite element DEFORM ${ }^{T M}-3 D$ software to investigate the plastic deformation behavior of magnesium billet during TC-ECAE process has been employed. Computed parameters including workpiece material characteristics and process conditions have been taken into consideration. The pridictions of strains distributions and damage distributions and effective stress distributions and flow velocities distributions and microstructures evolutions have been explored. The results proved that the TC-ECAE process is a forming method for magnesium alloy tube which is suitable for large scale industrial application. The TCECAE process would cause serve plastic deformation and improve the dynamic recrystallization of magnesium alloy during TC-ECAE process.

\section{Introduction}

Magnesium alloys have been used in transportation, communications, electronics and aerospace etc., and have become the focus concerned by all the countries in the world. Due to its hexagonal structure magnesium alloys can be deformed difficultly at room temperature for there is few separate slip system [1-2]. At present, the developed countries in the world have vigorously engaged in researches and development of magnesium alloy, and magnesium and magnesium alloys have been applied in the aerospace, defense industry, transportation, electronic devices shell, the field of sports equipment and office supplies.Accelerations of magnesium development have become an inevitable trend.

In recent years, some new manufacture processes and technologies in the field of casting such as pressure casting, semi-solid forming technology have been used to process new magnesium alloy material[3]. Comparing with casting process of the magnesium alloy productions, the plastic deformation processes can produe a variety of plate sizes, rods, tubes, profiles and forging products, and strength, ductility and mechanical properties of magnesium alloy are higher than those of magnesium alloy with as cast state.So it is very important to research and develop a new type of deformed magnesium alloy and new process to manufactue wrought magnesium alloy.

As the extrusion process is a method of plastic forming,and the material are formed under 3-directions compressive stresses, and it is suitable to form low plastic material, so the extrusion forming is an important method to produce the wrought magnesium alloy.In recent years, bulk nanostructure materials processed by severe plastic deformation (SPD) such as equal channel angular extrusion (ECAE) have attracted the growing interest of specialists in material science [4]. Alought it has been invented in the early 1980s, the process did not develop as much as one would desire and is still confined to the laboratory scale experiments[5-7]. 
It is commonly acknowledged that an extruded metal product may have non-uniform dimensions, excellent microstructures and advantageous mechanical properties.Although a constant ram speed is applied during extrusion process[8].

The varying strains and strain rates and temperatures are critical factors of the extrusion process. In recent years, the numerical simulation of extrusion process has become a new method to prevent defects,and advantageous tool to optimize the process and improve the quality of extruded products. Numerical simulations could be adopted to replace many of these experiments. The thermo-

mechanical responses of magnesium alloy as affected by extrusion conditions are highly complex. Local parameters, such as flow stress, strain, strain rate, and temperature, are not experimentally measurable. In such a case,Finite element(FE) simulation can play a unique role in gaining an understanding of the thermo-mechanical interactions which occur inside deforming material during extrusion. However, there is very few study on the simulation of $\mathrm{Mg}$ extrusion[9-10].

It is observed that, in general, the research on extrusion of magnesium alloy, making use of computer simulation as a tool in particular, has been highly insufficient. Much of the previous research is exploratory and often involves limited or unrealistic process parameters, or oversimplified simulation methods or even unreliable material models. Obviously, the simulation of extrusion to manufacture a light wall tube requires three dimensional (3D) FE simulations, which is at present still highly demanding on software, hardware, and user's skills[11-13].

In the present research, an attempt has been made to simulate the extrusion process which include direct extrusion and successive shearings to manufacture thin walled tube,which is shorten for "TC-ECAE" in this paper. The relationship between strain and stress evolution and process conditions is lacking. It concerned characterization of thermo-mechanical response of a wrought magnesium alloy during extrusion in terms of the evolutions of stress and strain and damage affected by extrusion. It is more complex than in the case of extruding the same billet into a tube, as a result of increased complexities in metal flow and stress distribution due to increased contact area and sharp edge.

To illustrate the potential industrial application of the TC-ECAE process, we designed the ES die used in the extruder and made simulation of TC-ECAE process. The pridiction microstructures of AZ61 Mg alloy sampled from tubes have been observed and analyzed. Deformed microstructure evolutions of the TCECAE process for AZ61 magnesium alloy have been studied in order to analyze the deformation mechanisms of TC-ECAE process. The aim of the present study is to clarify the grain refinements mechanism in AZ61 during TC-ECAE process. The present study employs DEFORM ${ }^{T M}-3 D$ finite element software to simulate the effective stress, extrusion force, strain evolution during TC-ECAE process. The microstructures evolutions and dynamic recrystallizations during period of extrusion-shearing of magnesium alloy have been researched.

\section{Simulation Conditions}


The description of the physical model includes the material properties of the billet, the forming temperature,and the friction law between the concave die and the workpiece.Wrought alloy AZ61 (Mg$6 \% \mathrm{Al}-2 \% \mathrm{Zn}$,w.t.\%) have been used in the simulation and extrusion experiments. The extrusion tooling consisting of die, container and ram was made of the $\mathrm{H} 13$ hot-work tool steel. The physical property of AZ61 is given in Table1. The curve of thermal conductivity of AZ61 shown in Fig. 1.

Table 1

Physical properties of AZ61

\begin{tabular}{|ll|}
\hline Property & Magnesium alloy AZ61 \\
\hline Heat transfer coefficient between tooling and billet $\left(\mathrm{N} /{ }^{\circ} \mathrm{C} \mathrm{s} \mathrm{mm}{ }^{2}\right)$ & 11 \\
\hline Heat transfer coefficient between tooling/billet and air $\left(\mathrm{N} /{ }^{\circ} \mathrm{C} \mathrm{s} \mathrm{mm}{ }^{2}\right)$ & 0.02 \\
\hline Poisson's Ratio & 0.25 \\
\hline coefficient of linear expansion $\left({ }^{\circ} \mathrm{C}^{-1}\right)$ & $2.58 \mathrm{E}-6$ \\
\hline Density $\left(\mathrm{kg} / \mathrm{m}^{3}\right)$ & 1780 \\
\hline poison's ratio & 0.45 \\
\hline Young's modulus(Mpa) & 47000 \\
\hline Emissivity & 0.12 \\
\hline
\end{tabular}

\subsection{Flow stress curves for AZ61 magnesium alloys}

Axial compression testing for hot workability analysis has been carried out using a Gleeble1500D machine with strain rate ranging from 0.01 to $10 \mathrm{~s}^{-1}$ and preheated temperature between $250^{\circ} \mathrm{C}$ and $500^{\circ} \mathrm{C}$. The flow stress curves are shown in Fig. 2 as examples with strain rates $0.01 \mathrm{~s}^{-1}$ and the different pre-set temperatures $250^{\circ} \mathrm{C}$ and $300^{\circ} \mathrm{C}$ and $350^{\circ} \mathrm{C}$ and $400^{\circ} \mathrm{C}$. The data have been input into the material property module of the DEFORM ${ }^{\mathrm{TM}}-3 \mathrm{D}$ software $[12,13,14]$.

\subsection{Contact and friction boundary conditions}

To represent the friction behavior as a consequence of the shear stress and the contact pressure, the generalized coulomb's law was used. The friction between the workpiece and die was considered as shear-type $[15,16,17]$ shown in equation (1).

$\tau=\frac{\mu \sigma}{\sqrt{3}}$

where $\tau$ is frictional shear stress and $\sigma$ is the effective flow stress of the workpiece.

2.3. Coefficient of heat transfer between AZ61 and die 
In this paper, the parameters in Table.2 were simulation parameters. The ambient temperature was considered as $20^{\circ} \mathrm{C}$, and temperature of TC-ECAE die $400^{\circ} \mathrm{C}$. The initial billet temperature has been chosen to be at a relatively high level $420^{\circ} \mathrm{C}$. Heat transfer coefficient between tooling and billet was $11 \mathrm{~N} /{ }^{\circ} \mathrm{Cs} \mathrm{mm}{ }^{2}$, and the value Heat transfer coefficients between tooling/billet and air are $0.02 \mathrm{~N} /{ }^{\circ} \mathrm{Cs}$ $\mathrm{mm}^{2}$ [14-15]. Emissivity coefficients of the AZ61 and $\mathrm{H}-13$ tool steel were 0.12 and 0.7 respectively. TCECAE process experiments were carried out to verify the results obtained from computer simulation in laboratory.

Table 2

Simulation and experimental parameters

\begin{tabular}{|ll|}
\hline Billet length $/ \mathrm{mm}$ & 100 \\
\hline Billet diameter $/ \mathrm{mm}$ & 80 \\
\hline Container insider diameter $/ \mathrm{mm}$ & 82 \\
\hline Container outside diameter $(\mathrm{mm})$ & 110 \\
\hline Die bearing length $(\mathrm{mm})$ & 6 \\
\hline extrusion ratio & 30 \\
\hline Initial tooling temperature $\left({ }^{\circ} \mathrm{C}\right)$ & 420 \\
\hline Initial billet temperature $\left({ }^{\circ} \mathrm{C}\right)$ & 400 \\
\hline Ram speed (mm/s) & 20 \\
\hline friction factor of the container-billet interface & 0.4 \\
\hline Friction factor between the billet and die. & 0.4 \\
\hline Total number of elements & 20000 \\
\hline Mesh density type & Relative \\
\hline Relative interference depth & 0.7 \\
\hline
\end{tabular}

\section{Numerical Simulation}

The longitudinal section schematic diagram of TC-ECAE process is schematically shown in Fig. 3 . The structure design of die is to match the size of the die with the blank size.The strength and the surface precision must be satisfied to obtain the surface quality of the pipe. The key parts of the die container are the extrusion die, the extrusion pad and the extrusion needle, and the different extrusion ratio can be obtained by changing the different sizes of extrusion needles. The die includes direction extrusion with extrusion ratio 28.1 and continuous shear structures with three section circular arcs.

\section{Results And Discussion}




\subsection{The curves of load and time}

The extrusion load could influent on the die life. Fig. 4 illustrates that loads caused by TC-ECAE die are various during extruding. The values for maximum forces have been obtained. The load curve can be divided into some stages obviously. At the initial stage of extrusion, when billet contacted with die corners, the billet began to be subjected to severe plastic deformation,and load increased to 920 ton,but this stage was not steady.The subsequent loads increased rapidly during direct extrusion, and billet continuously passed through the corners of the die. The situation correspond the time range where the die channel was filled with material. Further, the deformation load decreased as the entire billet went through the two channels. The deformation of billet was mainly achieved in this stage. During the third phase for the first shearing the average load is about 1200 ton. Subsequently tube of magnesium alloy is sheared by the first corner angle, and the maximum deformation load is as such as 1400 ton. When extrusion time is about $1.7 \mathrm{~s}$ and the TC-ECAE process is in the steady-stage of extrusion.

\subsection{Distributions of effective stress during an TC-ECAE process}

Examination of the predicted strains provides quantitative insight into deformation behavior of billet during TC-ECAE process [16-18]. It is necessary to understand the distributions and magnitudes of effective stresses are analyzed during TC-ECAE process. Fig. $\mathbf{5}$ shows the evolutions of effective stress contours in magnesium billet during different TC-ECAE steps, which provide the important information of stress distribution.Fig. 5a, Fig. $\mathbf{5 b}$ and Fig. $\mathbf{5 c}$ and Fig. $\mathbf{5 d}$ are the distributions of the equivalent stress for extrusion time $0.611 \mathrm{~s}, 0.73 \mathrm{~s}$ and $1.01 \mathrm{~s}$ and $2.27 \mathrm{~s}$ respectively. The effective stresses of the material are not even which are seen from the Fig. 5, and the maximum effective stress is about 1798MPa at extrusion time $0.611 \mathrm{~s}$. The deformation of the initial extrusion is nonuniform, and the highest stress $(3503 \mathrm{MPa})$ located at outer corner at extrusion time $0.73 \mathrm{~s}$. Distributions of the stress are lamellar with distinct deformation gradients. The deformation of position is close to the simple shear deformation, but the stress focus on deformation zone in the extrusion time $0.73 \mathrm{~s}$. The maximum stress increase to 3794 $\mathrm{MPa}$.From the stress evolution during the TC-ECAE process it can be found stress decrease with the TCECAE progressing ,the reason is that the dynamic recrystallization take place.

\subsection{Analysis of flow velocity}

Vector plots display magnitude and direction. Magnitude is indicated by vector length and color. Contour plots display only magnitude, where contour color indicaTC-ECAE velocity magnitude. Fig. 6 shows velocity field of metal flow during TC-ECAE process. An approximate sector with severe deformation in Fig. 6a and a dead metal zone exists near the export parts of die. Some metal moves perpendicular to the interface of the bottom die, while the other moves toward the container, and the dead zone are formed. Fig. 6a shows the dead metal zone where the material flow velocity is smaller than $75 \mathrm{~mm} / \mathrm{s}$, represented by the blue area at the corners between the container liner and die face. The flow discontinuity at the boundary between the deformation zone and dead metal zone is clearly revealed which is area of inactive 
metal that generally remains dormant and stagnant throughout the extrusion process. It is the shearing at this boundary which leads to the formation of extrusion surface from the virgin material in the interior of the billet. It was profitable that the dead metal zone kept the oxidated layer on the surface of billet staying in the container, and which prevent oxidated layer from entering the inner of workpiece.

While the front of flowing metal arrived at the lower underside of the die, a small static zone in Fig. $\mathbf{6 b}$ was formed when the direct extrusion stage was over. In the Fig. $\mathbf{6 c}$ and Fig. $\mathbf{6 d}$ the metal near the container flows towards the bottom die homogeneously, and less velocity vector toward the interfaces is observed in the plastic deformation zone, and the metal flows toward TC-ECAE die without large angle turning, which not only decreases the generation of flow lines turbulence, dead zone and overlaps, but also improves the extruded product quality.

\subsection{Damage pridiction}

Damage has been shown to be a good indicator of certain types of tensile ductile fracture. Workability is usually thought as being limited by the onset of the fracture. Greater workability of the material allows greater deformation. In this study many types of ductile fracture criteria were used to determine the limit of the bulk deformation. The empirical formulas of these criteria are described below. The modeling formulations of various ductility damage values are presented in Ref. [19-20]. The present study considers the following damage values in equation (2).

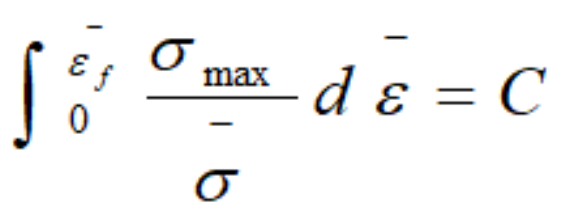

where $\sigma_{\max }$ is the maximum ductility stress; $\sigma_{1}$ and $\sigma_{2}$ are the principal stresses; $\sigma$ is the effective stress; $\varepsilon$ is the effective strain; $\sigma_{m}$ is the hydraulic compressive stress (mean stress); $n$ the strain hardening exponent; ${ }^{-} \varepsilon_{f}$ the effective strain of fracture; $F$ is a material deformation function; $C$ is the damage value of the material. In order to calculate ductile fracture criteria, destructive tests had been done and Compression tests have been carried out. Cockcroft and Latham predicted that fracture occurs in a ductile material at a critical damage factor value $C^{\star}$ of the damage factor $C$. The $C-L$ criterion for ductile fracture during metalworking was applied in conjunction with fracture strains measured from uniaxial tension tests. In uniaxial tension tests, in which sharp necks and high levels of stress triaxiality are negligible. The fracture $\operatorname{strain}^{-} \varepsilon_{f}$ derived from the AZ31 stress/strain curve is approximately 0.45 . Thus, the value of $C^{*}$ is 0.45 .

The experimental results showed that the fracture model adapted in these simulations was Cockcroft and Latham fracture model in equation (2) whose value was set to 0.45 . Fig. 7 represents the damage inclination indexes at extrusion time $0.611 \mathrm{~s}, 0.73 \mathrm{~s}, 1.01 \mathrm{~s}$ and $2.27 \mathrm{~s}$ respectively. It can be seen that the index of the damage at extrusion time $0.611 \mathrm{~s}$ is as much as 1 . And at the extrusion time 0.73 the index is 
about 0.9. It is seen that the maximum damage occurs at the billet surface in the exit region of the die. The reason could be attributed to the critical damage at the point of maximum tensile stress in the tube.

\subsection{Pridiction microstructure evolutions during TC-ECAE process}

Pridication microstructures evolutions of four parts in rod formed by TC-ECAE process are shown in Fig. 8. The microstructures with as cast state may appear splat shown in Fig. 8a, which indicates that the deformation degree is very small. As the deformation continues, the width of rod-like microstructures may become narrow, a number of lamellar-structure twins may appear in the grains shown in Fig. 8b,where dynamic crystallization would taken place. The uniform deformation takes place in the grains mainly and improves the formation of rod-like microstructures while recrystallization may occur in a small number of grains. Rod-like and lamellar microstructures fabricated by direct extrusion would began to reduce for the large shear strains caused by shear deformation in this zone and the deformation grains would turn into dynamic recrystallization grains shown in Fig. 8c.

In the shearing zones,dynamic recrystallization may happen sufficiently for six shearings, but there are still a small amount of fine-grain bar in the center of the rod shown in Fig. 8d.There are some inherent drawbacks for microstructures of extrusion process due to uneven metal flow during extrusion, and the properties from surface to the center were uneven. But the use of TC-ECAE process, the average grain size may be refined effectively.Microstructures are not only clearly refined but also relatively uniform. This is because the TC-ECAE process include additional six shearings and which is more than direct extrusion.So the deformation degree of central part of rods increase, part recrystallization occur.Therefore,the microstructures became smaller and more homogeneous.

The relationship between the average recrystallization grain size (d) and the Zener-Hollomon parameter (Z) during dynamic recrystallization is given by $-\operatorname{Ind}=\mathrm{A}+\mathrm{B}$ In Z . Based on the present TC-ECAE process with extrusion temperature $400^{\circ} \mathrm{C}$, average accumulative strains, strain rates and $Z$ parameters of the AZ61 increase with the development of TC-ECAE process[21-23]. It can be found that the accumulative strains increase with the extrusion advancing, so the grains will be refined consequently. It is clear that there are three phase recrystallization during TC-ECAE process. It can be found that the average sizes of grains for DRX were coarsened with the preheating temperature increasing and Z parameter decreases with the temperature.

\section{Conclusions}

This study has utilized three-dimensional finite element DEFORM software to research the plastic deformation behavior of magnesium billet during TC-ECAE process through a TC-ECAE combination die. The results have been shown as follows: The extrusion load curve can be divided into four stages including the extrusion upsetting stage and the direction extrusion stage and mulit-shearings obtained from simulation results. The evolutions of extrusion load curves and effective stresses and temperatures can be divided into four stages. The maximum damage occurs on the billet surface in the exit region 
owing to maximum tensile stress. The microstructures along forming direction have been pridicted. TCECAE extruded AZ61 sample could product fine-grained microstructures. The TC-ECAE process would cause serve plastic deformation and improve the dynamic recrystallization during TC-ECAE process. The results show that TC-ECAE is an efficient and inexpensive grain refinement method for magnesium alloys. Zener-Hollomon parameters during TC-ECAE process showed that the grains of magnesium would be refined gradually. The study indicates that FEM can be used confidently for designing extrusion dies and processes in CAE environment to improve upon the product quality and productivity by avoiding trail runs. The large strain rate can be introduced into the extrusion and continuous mulit-shearings deformation,which promote the occurrence of dynamic recrystallization of magnesium alloy, at the same time reduce or eliminate the defects in the interior of the microstructures. The deformation degree and uniformity of microstructures for the tube can be controlled by the preheated temperature and extrusion speed of TC-ECAE process. The strength and accuracy of pipe and grain refinements could be controlled.

\section{Declarations}

\section{Acknowledgement}

This work was supported by chongqing talent plan (CQYC202003047),and chongqing natural science foundation project of cstc2018jcyjAX0249 and cstc2018jcyjAX0653 ).

\section{-Ethical Approval}

No animals have been used in any experiments.

\section{-Consent to Participate}

There are no human who have been used in any experiments.

\section{Consent to Publish}

The Author confirms:

- that the work described has not been published before (except in the form of an abstract or as part of a published lecture, review, or thesis);

- that it is not under consideration for publication elsewhere;

- that its publication has been approved by all co-authors, if any;

- that its publication has been approved (tacitly or explicitly) by the responsible authorities at the institution where the work is carried out.

The Author agrees to publication in the Journal indicated below and also to publication of the article in English by Springer in Springer's corresponding English-language journal. 
The copyright to the English-language article is transferred to Springer effective if and when the article is accepted for publication. The author warrants that his/her contribution is original and that he/she has full power to make this grant. The author signs for and accepts responsibility for releasing this material on behalf of any and all co-authors. The copyright transfer covers the exclusive right to reproduce and distribute the article, including reprints, translations, photographic reproductions, microform, electronic form (offline, online) or any other reproductions of similar nature.

After submission of the agreement signed by the corresponding author, changes of authorship or in the order of the authors listed will not be accepted by Springer.

Journal:

Title in English :The International Journal of Advanced Manufacturing_Technology_

Title of article: A new method of manufacturing thin-walled tube made of AZ61 magnesium alloy. including direct extrusion and corrugated equal channel angular extrusion

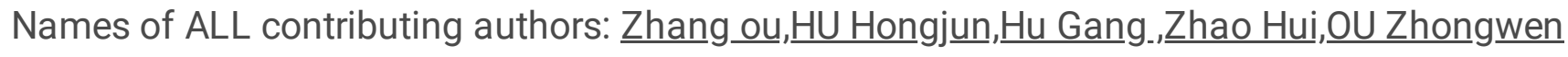

\section{-Authors Contributions}

- Zhang ou done the experiments in this paper.

- Hu Hongjun is corresponding author of this paper who wrote the paper.

- Hu Gang_done the simulation in this paper.

- Zhao Hui done the testings in this paper.

- OUZhongwen researahed the microstructures analysises in this paper

\section{-Funding}

This work was supported b chongqing talent plan (CQYC202003047), and chongqing natural science foundation project of cstc2018jcyjAX0249 and cstc2018jcyjAX0653).

I confirm that I have mentioned all organizations that funded my research in the Acknowledgements section of my submission, including grant numbers where appropriate.

\section{-Competing Interests}

The authors declare no competing non-financial/financial interests.

\section{-Availability of data and materials}

The raw/processed data required to reproduce these findings cannot be shared at this time as the data also forms part of an ongoing study. 


\section{Acknowledgement}

This work was supported by chongqing talent plan (CQYC202003047),and chongqing natural science foundation project of cstc2018jcyjAX0249 and cstc2018jcyjAX0653 ).

\section{References}

1. Han D, Zhang J, Huang JF, Yong L, He GY (2020) A review on ignition mechanisms and characteristics of magnesium alloys[J]. J Magnes Alloys 2:329-344. https://doi.org/10.1016/j.jma.2019.11.014

2. Giuliano G, Polini W (2021) Optimal design of blank thickness in superplastic AZ31 alloy to decrease forming time and product weight[J]. Int J Adv Manuf Technol. https://doi.org/10.1007/s00170-02108062-7

3. Yang $X$ et al (2021) Precipitation behavior of intermetallic compounds and their effect on mechanical properties of thick plate friction stir welded Al/Mg joint[J]. J Manuf Process 64:1059-1069

4. KUMAR S. DHARANI \& KUMAR S. SURESH(2021).Effect of heat treatment conditions on ballistic behaviour of various zones of friction stir welded magnesium alloy joints[J]. Transactions of Nonferrous Metals Society of China(1), doi:10.1016/S1003-6326(20)65484-X

5. Yuan S, Xia Q, Long J et al (2020) Study of the microstructures and mechanical properties of ZK61 magnesium alloy cylindrical parts with inner ribs formed by hot power spinning. Int J Adv Manuf Technol 111:851-860. DOI:10.1007/s00170-020-06091-2

6. Huang JF,G. L. Song,Zhu YX,D. J. Zheng,Z. M. Wang(2021)The anodically polarized Mg surface products and accelerated hydrogen evolution[J]. Journal of Magnesium and Alloys,DOI: 10.1016/j.jma.2021.05.008

7. Ji YF, Duan JR, Li HY et al. (2021)Improvement of edge crack damage of magnesium alloy by optimizing the edge curve during cross variable thickness rolling. Int J Adv Manuf Technol 112: 1993-2002,https://doi.org/10.1007/s00170-020-06517-x

8. Armin SIAHSARANI, FARAJI Ghader(2021)Processing and characterization of AZ91 magnesium alloys via a novel severe plastic deformation method: Hydrostatic cyclic extrusion compression (HCEC)[J]. Transactions of Nonferrous Metals Society of China(5), DOI:10.1016/S10036326(21)65579-6

9. Cai S, Li Q (2021) Analysis of the forming behaviors of magnesium alloy AZ31 by vaporizing metal foils. Int J Adv Manuf Technol 114:929-937. https://doi.org/10.1007/s00170-021-06970-2

10. Tian $\mathrm{Y}, \mathrm{Hu} \mathrm{H}$, Liang $P$ et al.(2021)Influences of expanding angles on extrusion-shearing-expanding processing of AZ31 magnesium alloy thin-walled tubes. Int J Adv Manuf Technol. https://doi.org/10.1007/s00170-021-07898-3

11. Chen Q, Zhang X, Lin J et al (2019) Isothermal closed-die forming process of magnesium alloy upper receiver: numerical simulation and experiments. Int J Adv Manuf Technol 102:685-694. https://doi.org/10.1007/s00170-018-03209-5 
12. Li XB, Li F, Li XW (2018) Effect of different temperatures on deformation characteristics of AZ31 magnesium alloy by continuous variable cross-section direct extrusion. Int $\mathrm{J}$ Adv Manuf Technol 95:4623-4628 https://doi.org/10.1007/s00170-017-1557-6

13. Xia-wei YANG,Wu-yuan FENG,Wen-ya LI, Shuo-tian YAO(2019)Microstructure and properties of probeless friction stir spot welding of AZ31 magnesium alloy joints[J].Transactions of Nonferrous Metals Society of China(11), doi:10.1016/S1003-6326(19)65136-8

14. Moradnezhad S, Razaghian A, Taghiabadi R et al.(2019)Effect of Ca additions on evolved microstructures and subsequent mechanical properties of a cast and hot-extruded $\mathrm{Mg}-\mathrm{Zn}-\mathrm{Zr}$ magnesium alloy. Int J Adv Manuf Technol 104:4265-4275. https://doi.org/10.1007/s00170-01904260-6

15. Wang YP, Li F, Li XW(2020)Effect of extrusion ratio $(\lambda)$ on dynamic recrystallization of AZ31 magnesium alloy bending products prepared by staggered extrusion (SE). Int J Adv Manuf Technol 108:289-297. https://doi.org/10.1007/s00170-020-05416-5

16. Han S, Li Z, Wang Z et al (2021) Review on joining processes of magnesium alloy sheets. Int J Adv Manuf Technol. https://doi.org/10.1007/s00170-021-07981-9

17. Wang Y, Li F, Li XW et al.(2019)Process model and experimental analysis of circumferential extending extrusion forming for magnesium alloy sheet. Int $\mathrm{J}$ Adv Manuf Technol 102:1547-1556. https://doi.org/10.1007/s00170-018-03232-6

18. Xia X, Xiao L, Chen Q et al (2018) Hot forging process design, microstructure, and mechanical properties of cast Mg-Zn-Y-Zr magnesium alloy tank cover. Int J Adv Manuf Technol 94:4199_ 4208. https://doi.org/10.1007/s00170-017-1146-8

19. Su C, Zhang M, Yang $\mathrm{H}$ et al (2021) Study on forming limit of single-point progressive forming of AZ31B magnesium alloy under isothermal local loading. Int J Adv Manuf Technol. https://doi.org/10.1007/s00170-021-07935-1

20. Hu H, Hong X, Tian $Y$ et al (2021) AZ31 magnesium alloy tube manufactured by composite forming technology including extruded-shear and bending based on finite element numerical simulation and experiments. Int J Adv Manuf Technol 115:2395-2402. https://doi.org/10.1007/s00170-021-072429

21. Wu S, Sun T, Shen $Y$ et al.(2021)Conventional and swing friction stir spot welding of aluminum alloy to magnesium alloy. Int J Adv Manuf Technol 116: 2401-2412. https://doi.org/10.1007/s00170020-06548-4

22. Campanella D, Buffa G, Lo Valvo E et al (2021) A numerical approach for the modelling of forming limits in hot incremental forming of AZ31 magnesium alloy. Int J Adv Manuf Technol 114:32293239. https://doi.org/10.1007/s00170-021-07059-6

23. Xu J, Wang Y, Wen $Z$ et al.(2020)Electromagnetic impacting medium forming (EIMF): a new method forming process for magnesium alloy sheet. Int J Adv Manuf Technol 109:553-563. https://doi.org/10.1007/s00170-020-05660-9 
Figures

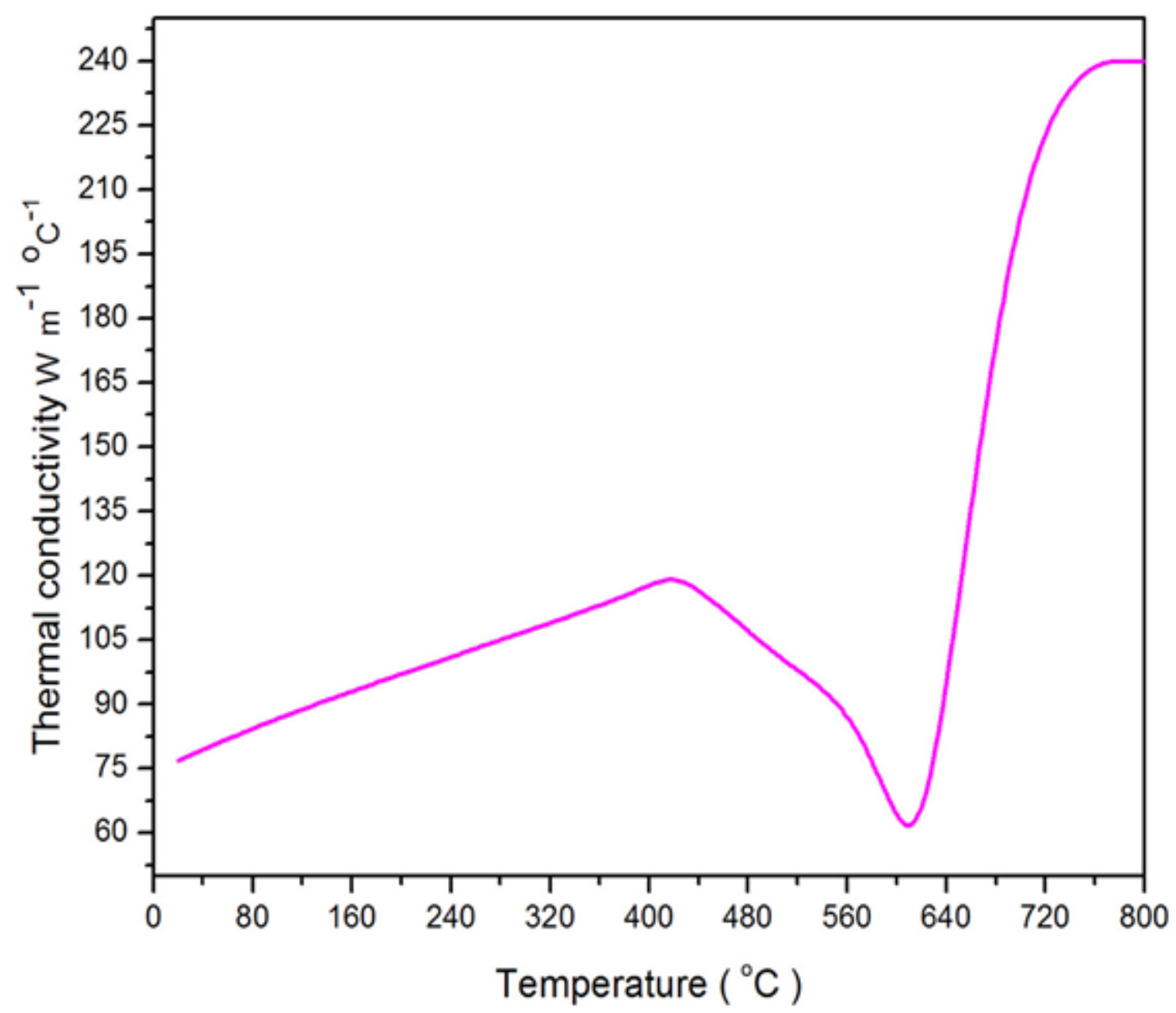

Figure 1

Curve of thermal conductivity of AZ61 magnesium alloy. 


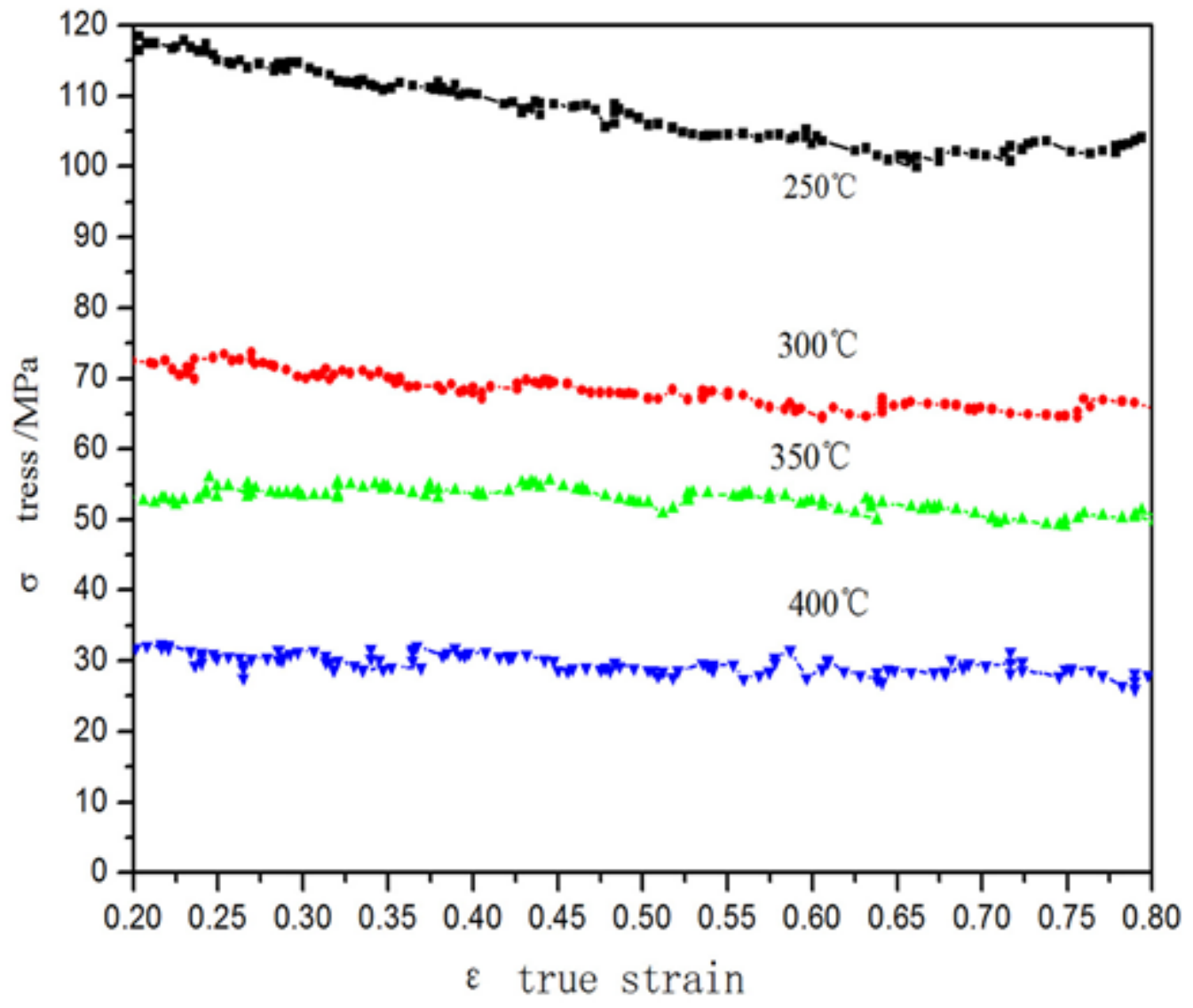

Figure 2

Examples of stress/strain curves. 


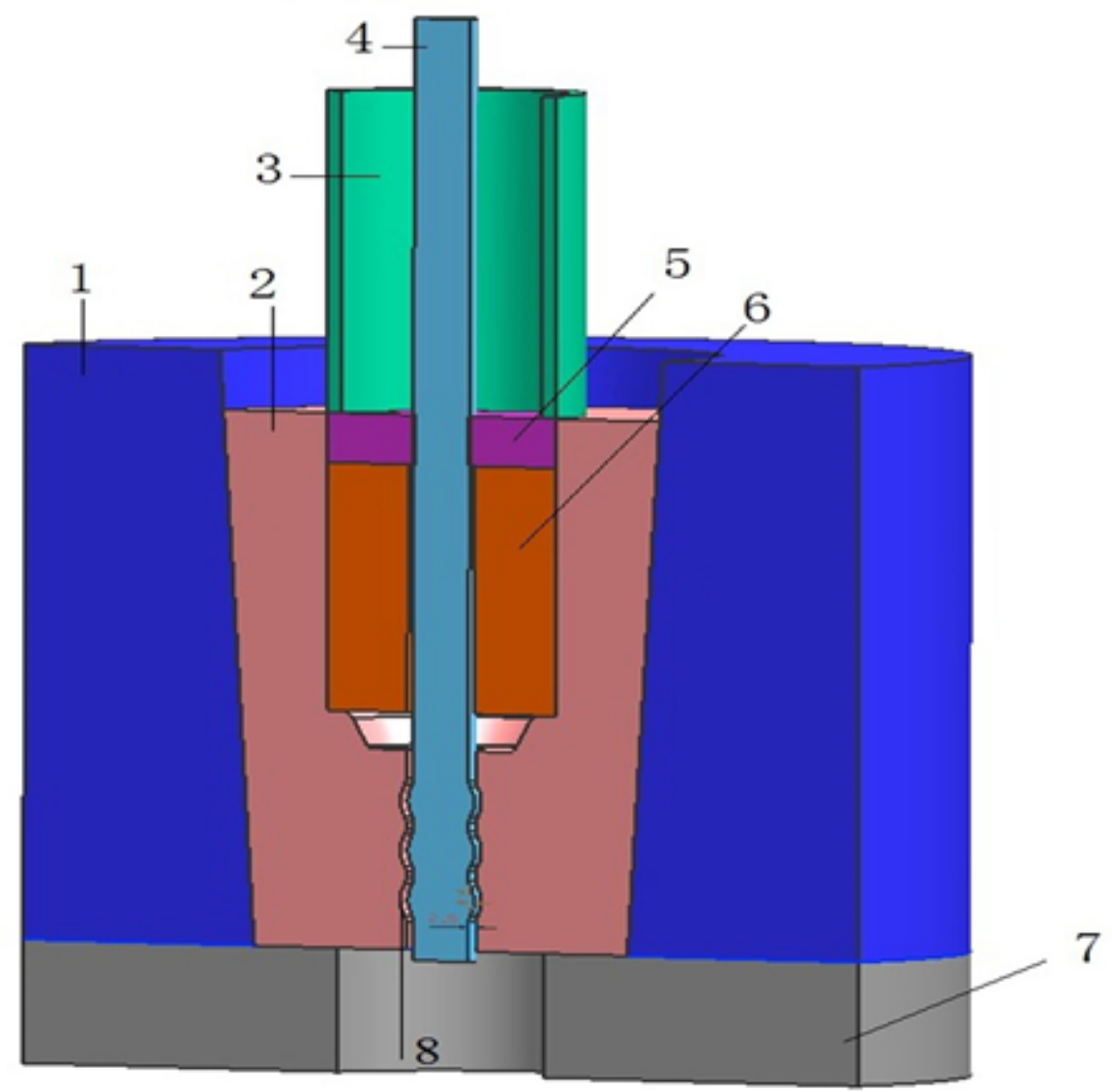

Figure 3

Combined concave die and billet,1-jackets of combined concave die,2-inner sleeve of combined concave die,3-Extrusion shaft,4-Fixed extrusion mandrel,5-Dummy block,6- Hollow blank,7-Foundation,8Continuous shear structures with three section circular arcs. 


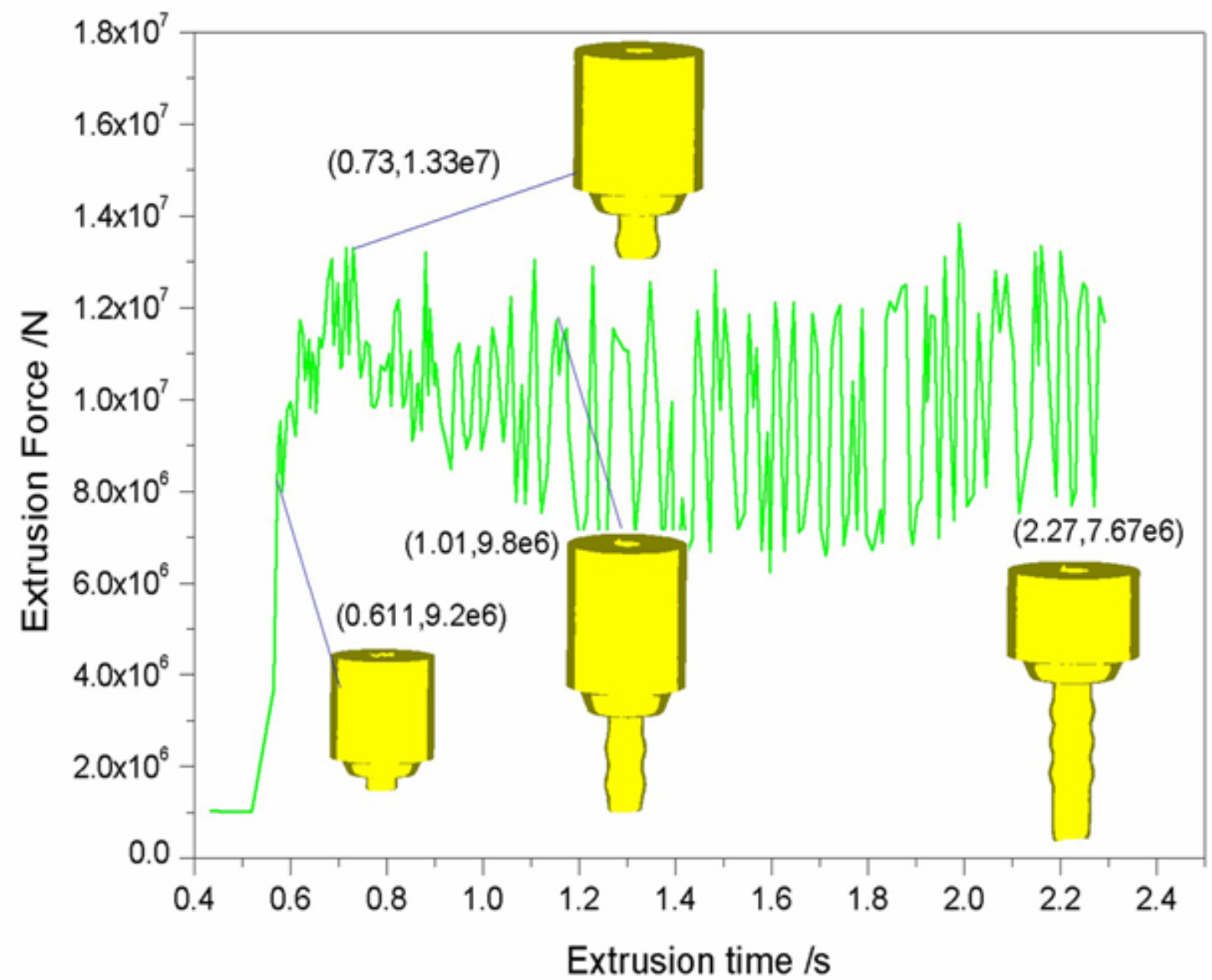

Figure 4

The extrusion loads during TC-ECAE process of AZ61 magnesium alloy. 


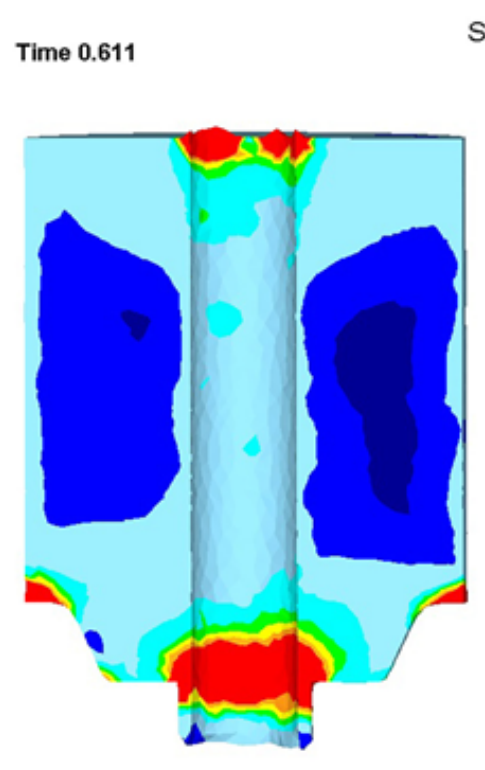

(a)

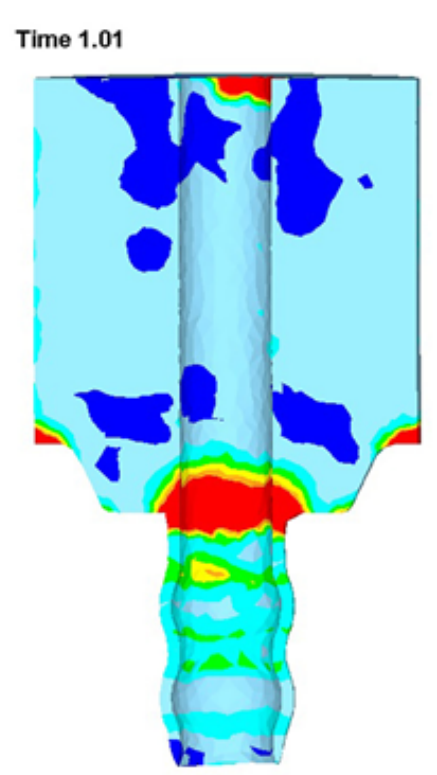

(b)
Stress - Effective (MPa)

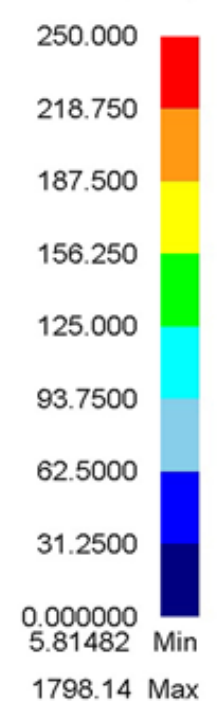

Stress - Effective (MPa)

250.000
218.750
187.500
156.250
125.000
93.7500
62.5000
31.2500
$0.000000 \quad$ Min
$3.06520 \quad$ Max
3794.71 Max

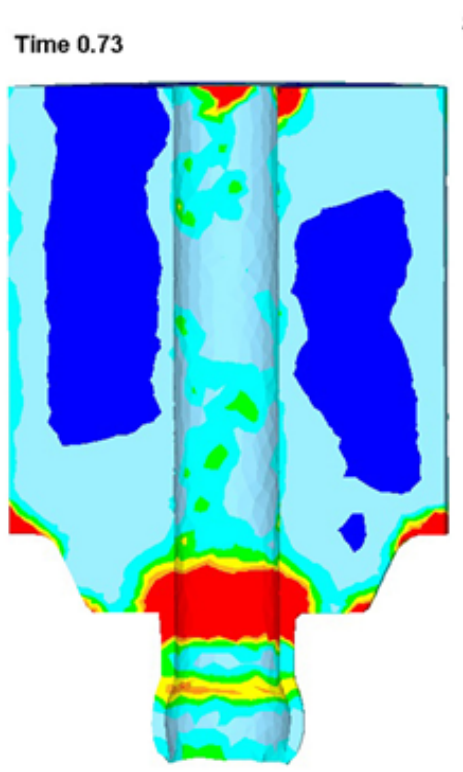

Stress - Effective (MPa)

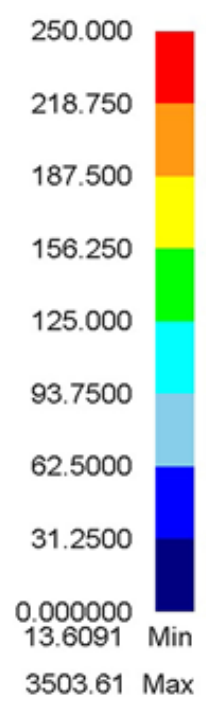

(b)

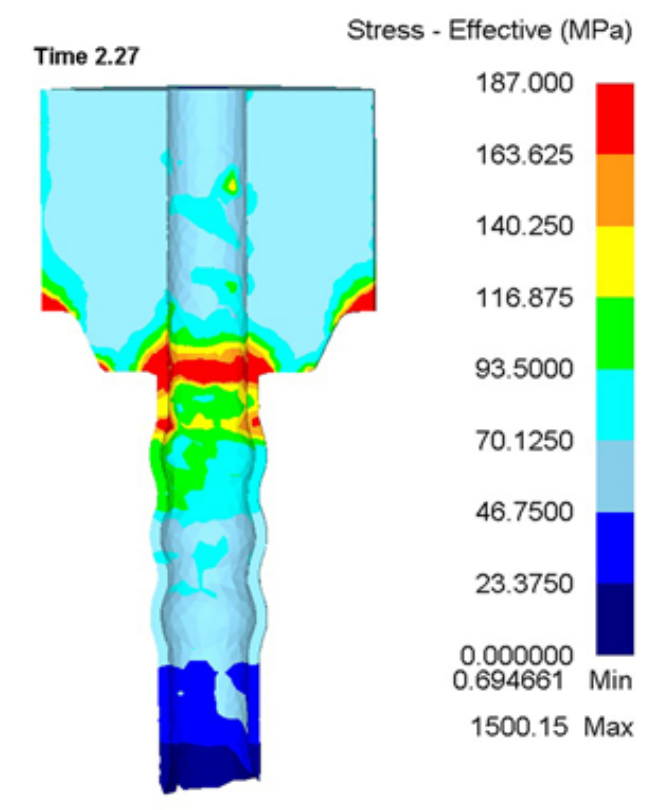

(d)

\section{Figure 5}

The evolutions of effective stress contours in billet during different time for TC-ECAE process, (a) $0.611 \mathrm{~s}$, (b) $0.73 \mathrm{~s},(\mathrm{c}) 1.01 \mathrm{~s}$ and (d) $2.27 \mathrm{~s}$. 


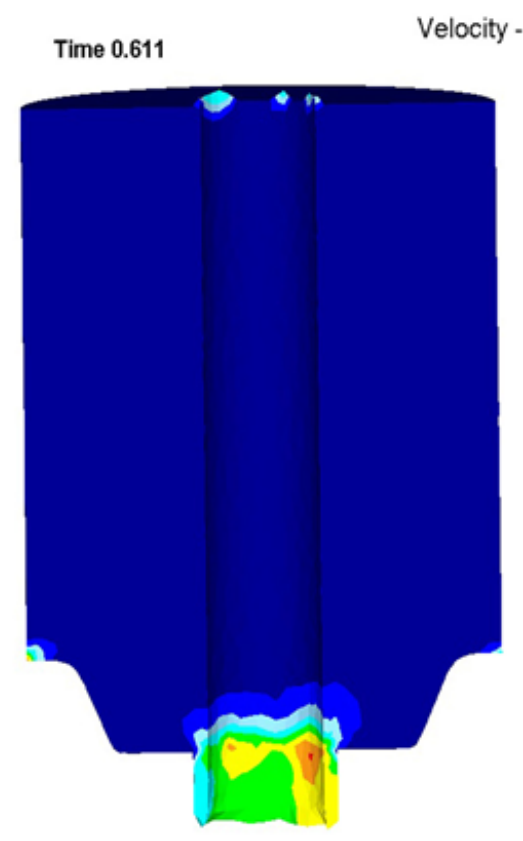

(a)

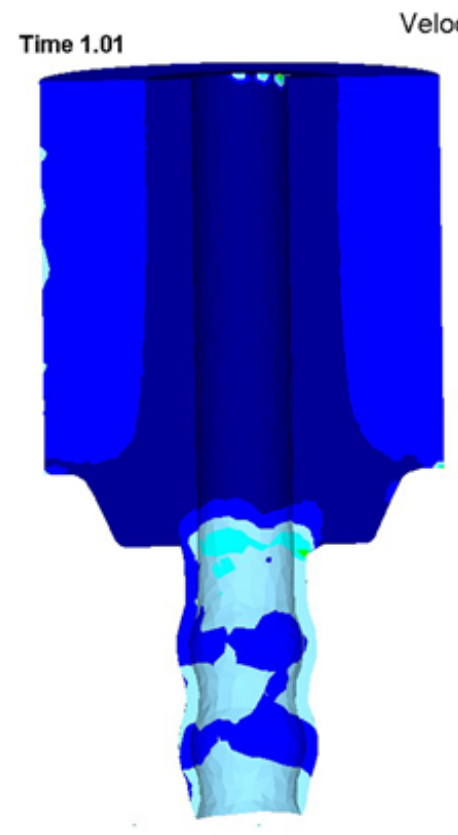

(c)
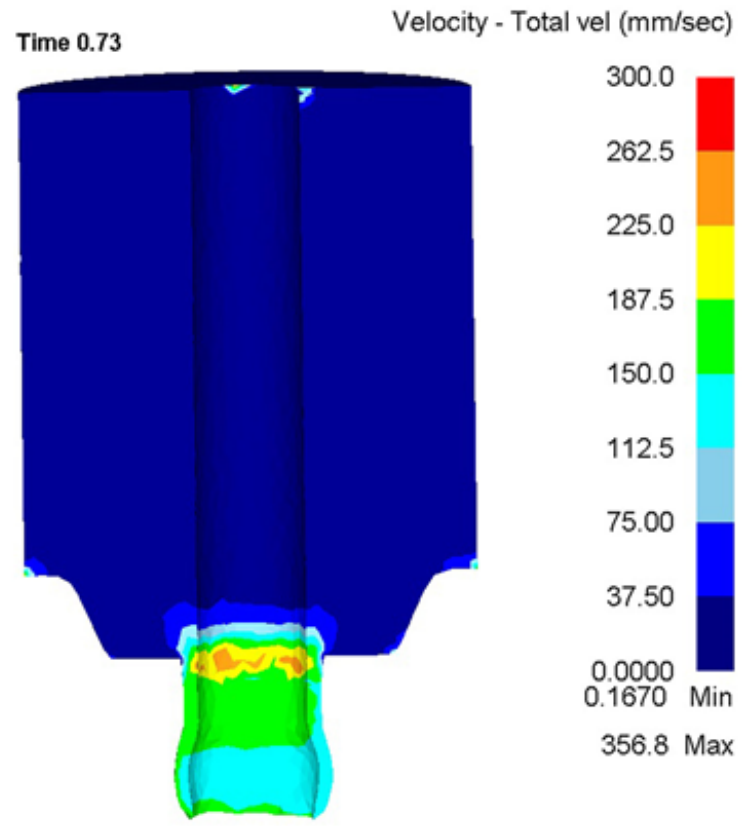

(b)

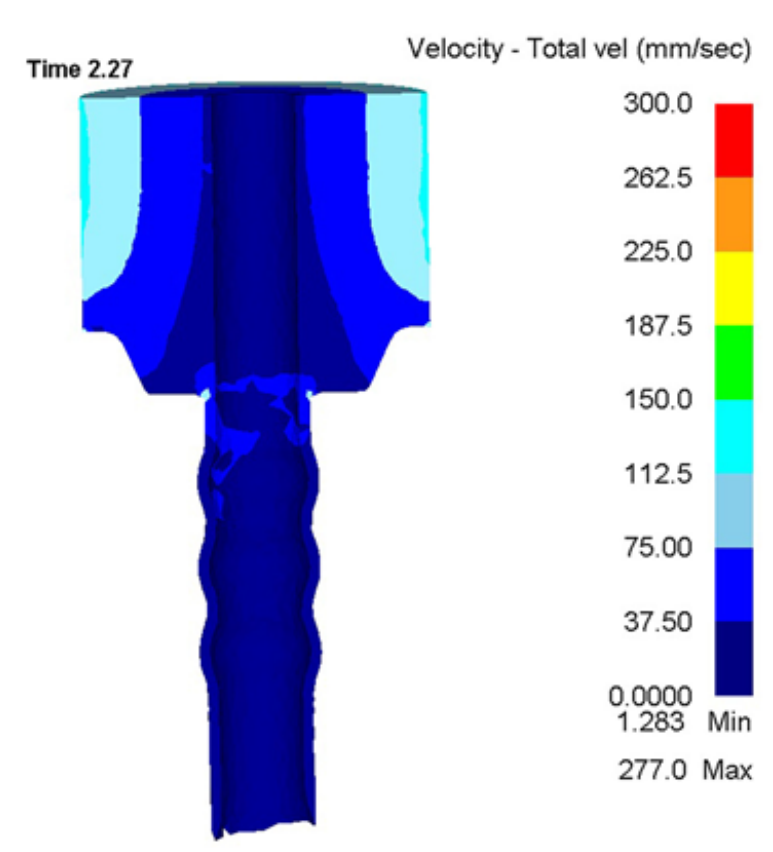

(d)

\section{Figure 6}

The flow velocity fields during TC-ECAE process,(a)0.611s,(b)0.73s,(c)1.01s and (d)2.27s. 

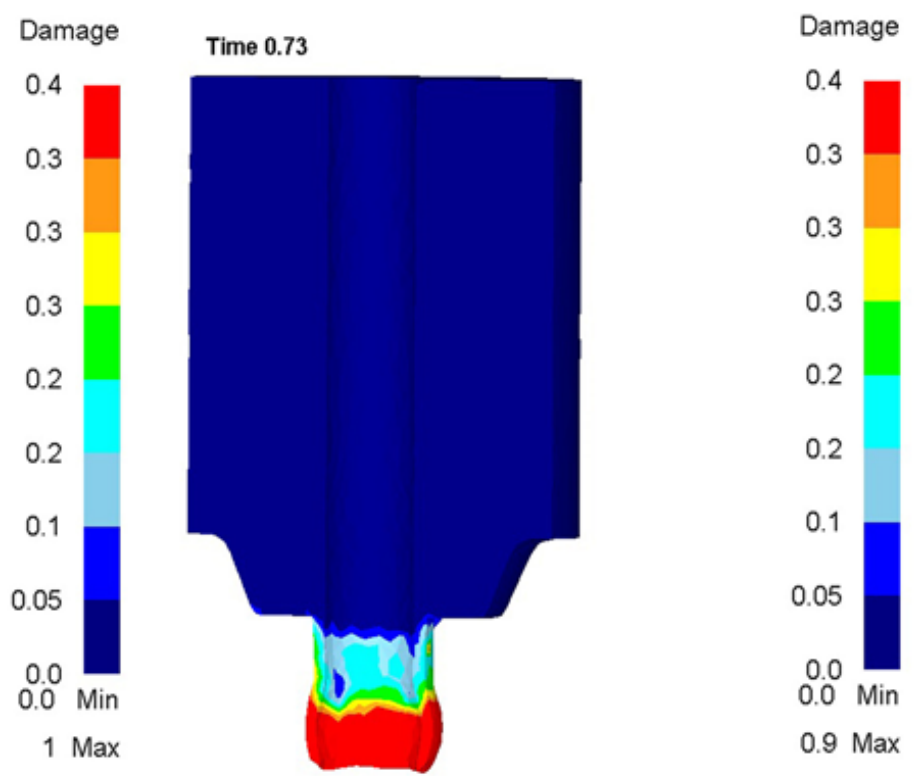

(a)

(b)

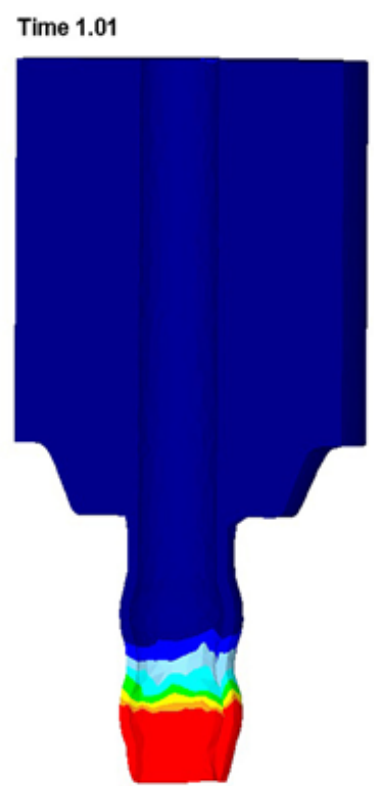

(c)

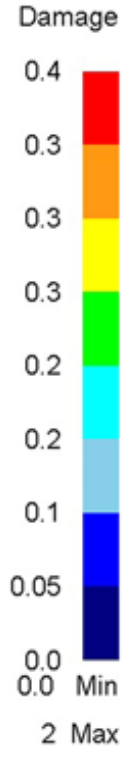

(d)
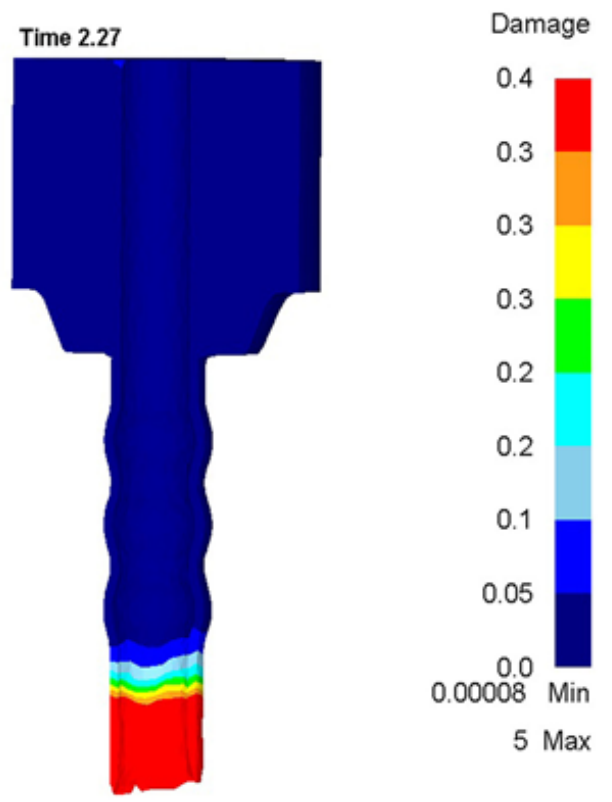

\section{Figure 7}

Crack initiation predicted by normalized Crokcroft and Latham fracture model,(a)0.611s,(b)0.73 s, (c)1.01s and (d)2.27s. 

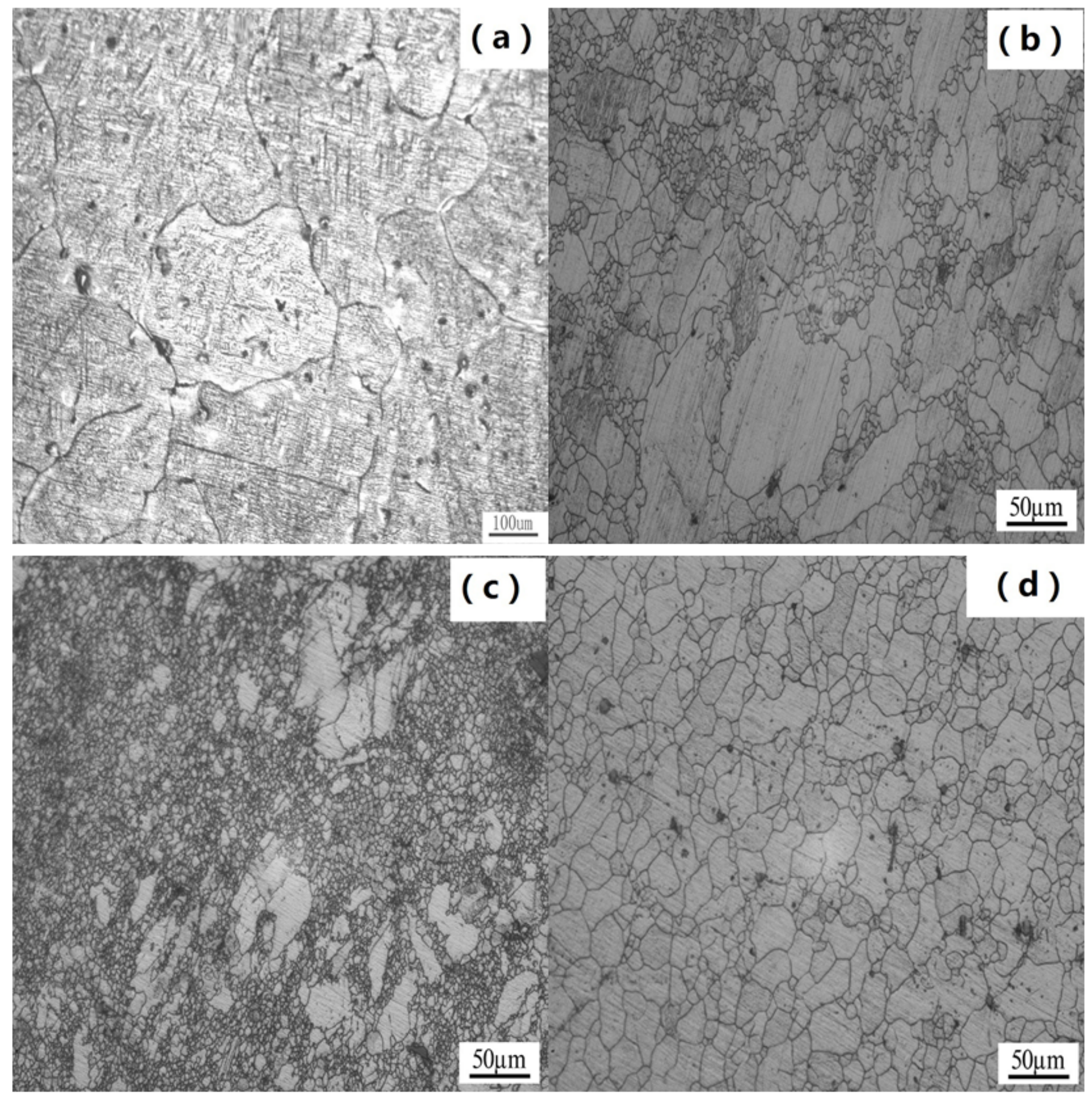

\section{Figure 8}

Pridication microstructures of AZ61 magnesium alloy in different part of TC-ECAE die (a) $0.611 \mathrm{~s},(\mathrm{~b}) 0.73$ $\mathrm{s},(\mathrm{c}) 1.01 \mathrm{~s}$ and (d) $2.27 \mathrm{~s}$. 